\title{
A Randomized Study on the Efficacy of Music Therapy on Pain and Anxiety in Nasal Septal Surgery
}

\author{
Avinash Gogoularadja ${ }^{1}$ Satvinder Singh Bakshi ${ }^{2}$ \\ ${ }^{1}$ Mahatma Gandhi Medical College and Research Institute (MGMCRI), \\ Sri Balaji Vidyapeeth, Pillaiyarkuppam, Pondicherry, India \\ 2 Department of Ear, Nose and Throat and Head \& Neck Surgery, \\ All India Institute of Medical Sciences (AlIMS), Mangalagiri, Guntur, \\ Andhra Pradesh, India
}

\begin{abstract}
Address for correspondence Dr. Satvinder Singh Bakshi, MS, DNB, Department of Ear, Nose and Throat and Head \& Neck Surgery, All India Institute of Medical Sciences (AlIMS), House number 1A, Selvam apartments, 71, Krishna Nagar main road, Krishna Nagar, Pondicherry 605008, India (e-mail: saty.bakshi@gmail.com).
\end{abstract}

Int Arch Otorhinolaryngol 2020;24(2):e232-e236.

\begin{abstract}
Keywords

- music therapy

- anxiety

- pain management

- morbidity

- nasal surgical procedure

Introduction Nasal septal surgery is one of the most common surgeries performed by otolaryngology surgeons; however, anxiety before surgery and postoperative pain remain a significant cause of morbidity. The search for a complimentary modality to reduce the symptoms and side effects has gained momentum in recent years.

Objective Music therapy is an exciting and inexpensive modality in this regard, but scientific evidence in terms of randomized clinical trials is still lacking for common otolaryngology surgeries. Hence, we performed the present study.

Method The sample of our study was composed of 59 patients, 30 of which were submitted to conventional medicine, while the remaining 29 were submitted to both conventional medicine and music therapy with music of their own choice, with 2 sessions per day, each lasting 30 minutes. This was performed using the generalized anxiety disorder-7 scale and the pain visual analogue scale until postoperative day 2 , when the patients were discharged from the hospital.

Result On comparing the anxiety and pain scores between the two groups, the group who underwent music therapy showed a statistically significant reduction in anxiety both preoperatively $(p<0.0001)$ and postoperatively $(p<0.0001)$, as well as reduced postoperative pain starting from day $0(p<0.001)$, which continued until postoperative day $2(p<0.001)$.

Conclusion Music therapy is an effective adjunct in the control of anxiety and postoperative pain following nasal septal surgery.
\end{abstract}

\section{Introduction}

Surgery on the nasal septum is one of the most common surgeries performed in the ear, nose and throat (ENT) practice. $^{1}$ Postoperative pain is a major concern among patients undergoing the surgery. ${ }^{2}$ It causes decrease in appetite, disturbance in sleep, and reduces the quality of life. Even though anxiety and postoperative pain can be reduced by large doses of anxiolytic drugs and analgesics, these drugs can depress circulation and respiration and have many side effects, making non-drug alternatives particularly attractive. Recently, several adjuncts have been used to reduce postoperative pain, like hypnosis, ${ }^{3}$ acupuncture, ${ }^{4}$ infiltrating nasal packs with topical anesthetics ${ }^{5-7}$ etc.

Music interventions have been used as a way of ameliorating pain and distress for patients with various medical issues. Their efficacy in reducing postoperative pain and anxiety has also been proven in many other surgeries. They offer a safe received

April 10, 2019

accepted

October 28, 2019

published online

February 27, 2020
DOI https://doi.org/

10.1055/s-0039-3402438. ISSN $1809-9777$.
Copyright (e 2020 by Thieme Revinter

Publicações Ltda, Rio de Janeiro, Brazil
License terms

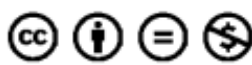


and cost-effective adjunct to standard surgical care. ${ }^{8}$ Music provokes positive auditory stimuli that can mask adverse sound stimuli, ${ }^{9}$ influence biochemical production, ${ }^{10}$ improve emotional health through normalization of an unfamiliar environment, ${ }^{11}$ and provide a sense of hope and enhanced well-being. ${ }^{12}$ The literature reveals that music therapy interventions are effective in reducing anxiety, postoperative pain and anesthesia requirements. ${ }^{13}$ Music therapy plays an important role in reducing pain and anxiety in many procedures, such as insertion of intravenous lines, ${ }^{14}$ immunization, ${ }^{15}$ lumbar procedures, ${ }^{16}$ laceration repair, ${ }^{17}$ burn debridement, ${ }^{18}$ and dental procedures. ${ }^{19}$ A randomized control trial ${ }^{20}$ of music therapy to patients undergoing flexible sigmoidoscopy or colonoscopy found that the patients in the music group reported lower pain levels, less administrations of sedation and shorter examination times.

There are no randomized studies in the literature in English evaluating the efficacy of music therapy on nasal septal surgeries. Therefore, we performed the present study to prove the efficacy of music therapy in reducing postoperative pain and anxiety in patients undergoing nasal septal surgery

\section{Materials and Method}

\section{Subjects}

The present randomized control study was approved by the institutional Review Board (approval number ICMR STS PROJECT 2017/05/08) and Ethics Committee, and was performed on patients who were scheduled for nasal septal surgery in the hospital from May to August 2017. The patients who were willing to participate in the study were aged between 18 and 55 years and had clinical and radiological evidence of deviated nasal septum. Patients were excluded if they had a significant hearing loss, neurological disorders, narcotic dependence due to another condition, hypertension, or if they were undergoing any other nasal surgery. After obtaining clearance from the Ethics Committee and informed consent from the patients, the sample underwent a thorough history taking and clinical examination, which were recorded in the proforma. These patients were randomized by the investigator using computergenerated random numbers into two study groups. Group A was submitted to routine postoperative care and analgesics. Group B was submitted to routine postoperative care and analgesics along with music therapy. The methodology is depicted in - Fig. $\mathbf{1}$.

\section{Septoplasty}

The procedure was performed under general anesthesia, and all of the surgeries were performed by the same surgeon. The septum was infiltrated with $2 \%$ lignocaine with 1:100,000 adrenaline, after which an incision was made $5 \mathrm{~mm}$ behind the mucocutaneous junction of the septum. The subperichondrial flap was elevated using a cottle elevator (Jullsurgicals, New Delhi, India), and the deviated portion of the septum was identified. This deviated portion was then incised with a knife and removed, carefully preserving the mucoperichondrial flap on the other side. Hemostasis was achieved, and the flap was resutured with 3-0 chromic catgut sutures (Orion sutures, Bengaluru, Karnataka, India). The nose was then packed with antiseptic soaked gauze. The nasal pack was removed on postoperative day 1 , and the patient was discharged on postoperative day 2 .

\section{Music}

Music therapy was administered by using headphones along with music chosen by the patients. The patients were asked to

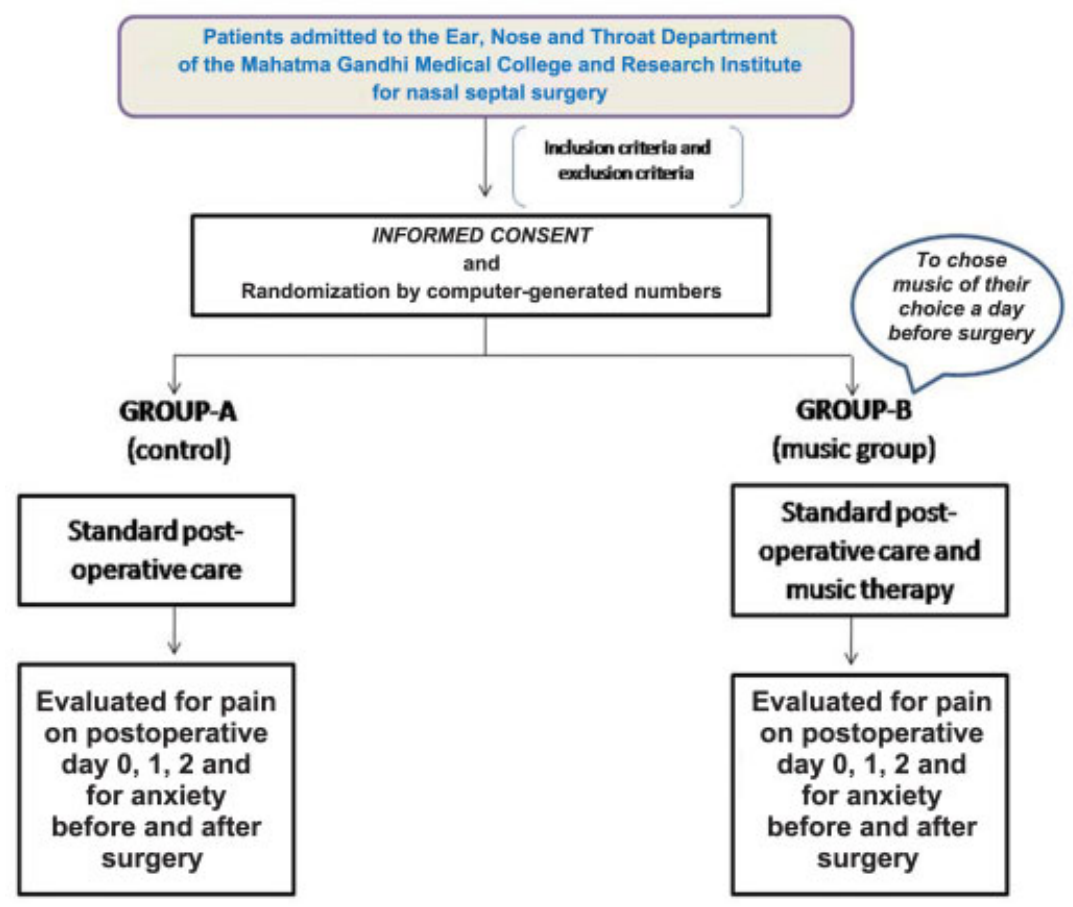

Fig. 1 Methodology chart showing the distribution of patients 
identify music that would calm them one day before the surgery. There were 2 sessions per day, each lasting 30 minutes. The sessions took place just before the surgery and for 2 postoperative days. Headphones were connected to a music player, and the music chosen was played at a comfortable level determined by the patients to relax them. The pre- and postoperative anxiety score was assessed using the Generalized Anxiety Disorder-7 (GAD-7) scale, which is composed of seven points and is used to screen and measure the severity of the anxiety. This scale has a set of seven questions; each question is scored from 0 to 3. To assess postoperative pain, the pain visual analogue scale (VAS) was used, which contains six faces ranging from a happy, smiley face to a sad and crying face. The faces are numbered from 0 (happy face - no pain) to 10 (saddest face -worst pain), with the numbers going up in increments of two $(0,2,4,6,8,10)$. The patient picked the face that best depicted his or her own pain, and the investigator recorded the assigned number to that face.

\section{Outcomes}

The data was collected using a proforma sheet. The privacy and confidentiality of the patients was guaranteed. All patient identifiable numbers and information were stripped and replaced by anonymous numbers. The collected data were transferred to an Excel (Microsoft Corp., Redmond, WA, US) spreadsheet, and the results were analyzed in the end by a blinded investigator.

\section{Statistical Analysis}

The statistical analysis was performed using the Statistical Package for the Social Sciences (SPSS, IBM Corp., Armonk, NY, US) software, version 21.0. All quantitative variables were estimated using measurements of central location (that is, mean and median) and measurements of dispersion (that is, standard deviation [SD]).

The scores on the pain VAS and GAD-7 were analyzed by the Mann-Whitney $U$ test when comparing both groups, and by repeated measures of analysis of variance (ANOVA) in the case of intragroup comparisons. Values of $p<0.05$ were considered statistically significant.

\section{Results}

A total of 30 patients composed each group; the patients in group A (the control group) were submitted to standard postoperative care, and the patients in group B (the music therapy group) were submitted to standard postoperative care along with music therapy. One patient in the music therapy group did not complete the follow-up, as he had to be discharged early due to personal reasons; therefore, the number of patients in the music group was reduced to 29 .

\section{Patient Population}

No statistically significant differences were found between the groups in terms of age (group A: $34.20 \pm 1.81$; group B: $33.83 \pm 2.14 ; p=0.895$ ) and gender (group A: 13 females and 16 males; group B: 8 females and 22 males; $p=0.145$ ). A summary of the patient demographics is provided in - Table 1
Table 1 Patient demographics

\begin{tabular}{|l|l|l|l|}
\hline & $\begin{array}{l}\text { Group A } \\
(\boldsymbol{n}=\mathbf{3 0})\end{array}$ & $\begin{array}{l}\text { Group B } \\
(\boldsymbol{n}=\mathbf{2 9})\end{array}$ & $\begin{array}{l}\text { Statistical } \\
\text { difference } \\
(\boldsymbol{p} \text {-value })\end{array}$ \\
\hline $\begin{array}{l}\text { Average age in years } \\
\text { (standard deviation) }\end{array}$ & $\begin{array}{l}33.83 \\
(11.75)\end{array}$ & $\begin{array}{l}34.20 \\
(9.76)\end{array}$ & 0.895 \\
\cline { 1 - 3 } Female & 8 & 13 & 0.145 \\
\cline { 1 - 3 } Male & 22 & 16 & \\
\hline
\end{tabular}

\section{Scores}

There was a significant reduction in the postoperative pain scores in both the groups, with the pain score decreasing from $6.67 \pm 1.40$ to $4.67 \pm 0.85$ in the control group $(p<0001)$ and from $3.03 \pm 1.35$ to $0.79 \pm 0.74(p<0.0001)$ in the music group. However, the decrease in postoperative pain in the music group was found to be statistically significant when compared with that of the control group on postoperative days $0(p<0.001), 1(p<0.001)$ and $2(p<0.001)$ (-Table 2$)$. The difference in the preoperative (group A: $6.73 \pm 2.32$; group $B: 3.14 \pm 1.71 ; p<0.0001$ ) and postoperative anxiety scores (group A: $8.93 \pm 2.20$; group B: $2.86 \pm 2.33 ; p<0.0001$ ) for both groups was statistically significant, with reduced anxiety in the music therapy group (-Table 3 ).

\section{Discussion}

The present study found a significant reduction in postoperative pain and anxiety, and a reduced need for analgesics in patients who underwent music therapy compared with

Table 2 Comparison of the postoperative pain Visual Analogue Scale scores

\begin{tabular}{|l|l|l|l|}
\hline Postoperative pain & Group A & Group B & p-value \\
\cline { 2 - 4 } & $\begin{array}{l}\text { Mean } \\
\text { (standard } \\
\text { deviation) }\end{array}$ & $\begin{array}{l}\text { Mean } \\
\text { (standard } \\
\text { deviation) }\end{array}$ & $\begin{array}{l}\text { Mann } \\
\text { Whitney } \\
\text { test }\end{array}$ \\
\hline Day 0 & $6.67(1.40)$ & $3.03(1.35)$ & $<\mathbf{0 . 0 0 1}$ \\
\hline Day 1 & $6.28(1.17)$ & $1.83(1.30)$ & $<\mathbf{0 . 0 0 1}$ \\
\hline Day 2 & $4.67(0.85)$ & $0.79(0.74)$ & $<\mathbf{0 . 0 0 1}$ \\
\hline $\begin{array}{l}\text { p-value (repeated } \\
\text { measures analysis } \\
\text { of variance) }\end{array}$ & $<\mathbf{0 . 0 0 0 1}$ & $<\mathbf{0 . 0 0 0 1}$ & \\
\hline
\end{tabular}

Table 3 Comparison of pre- and postoperative anxiety

\begin{tabular}{|l|l|l|l|}
\hline Parameter & Group A & Group B & p-value \\
\cline { 2 - 3 } & $\begin{array}{l}\text { Mean } \\
\text { (standard } \\
\text { deviation) }\end{array}$ & $\begin{array}{l}\text { Mean } \\
\text { (standard } \\
\text { deviation) }\end{array}$ & \\
\hline $\begin{array}{l}\text { Preoperative } \\
\text { anxiety }\end{array}$ & $6.73(2.32)$ & $3.14(1.71)$ & $<\mathbf{0 . 0 0 0 1}$ \\
\hline $\begin{array}{l}\text { Postoperative } \\
\text { anxiety }\end{array}$ & $8.93(2.20)$ & $2.86(2.33)$ & $<\mathbf{0 . 0 0 0 1}$ \\
\hline
\end{tabular}


those who did not. This is consistent with works like those of Good et al, ${ }^{21}$ who proved, in a study with 311 gynecologic surgery patients, that patients exposed to music used less analgesics. Similarly, Keilani et $\mathrm{al}^{22}$ conducted a study on the efficacy of music therapy as an adjunctive therapy for pain relief in ambulatory maxillofacial and otolaryngology surgeries, and they found music to be very effective in reducing postoperative pain and anxiety in 19 patients. McCaffrey et $\mathrm{al}^{23}$ proved that elderly people who listened to music 20 minutes a day for 2 weeks had reduced chronic osteoarthritis pain compared with the control group, whose pain values remained constant. A randomized trial of 150 patients undergoing varicose vein surgery found a significant short-term pain reduction in the music group compared with the control group, regardless of whether music was played during or after surgery. ${ }^{24}$

Listening to music may have a wide range of therapeutic effects in patients by relieving anxiety, stimulating sedation, relaxing and reducing emotional and stress response to unpleasant stimuli by distraction. Music therapy causes positive physiologic changes, such as decreased serum cortisol levels and an increase in the level of salivary immunoglobin. ${ }^{25}$ There is a release of corticotrophin-releasing hormone (CRH) from the pituitary gland in response to a perceived stressful event that eventually leads to the stimulation of the adrenal medulla, releasing adrenaline into the blood circulation. Adrenaline causes tachycardia, raised blood pressure and a host of undesirable effects. Music therapy helps control these events by a negative feedback on the production of $\mathrm{CRH}{ }^{26,27}$

Music can improve the mood and reduce anxiety in surgical patients, as demonstrated in a study ${ }^{28}$ on patients undergoing prostate surgery: the patients submitted to a music intervention had significantly reduced anxiety and blood pressure. Patients about to undergo surgery with spinal anesthesia who listened to music required less sedatives to achieve a similar degree of relaxation compared with the control group. ${ }^{29}$ In a study ${ }^{30}$ of 20 women awaiting breast biopsy, the group that listened to 20 minutes of music had less anxiety than the patients submitted to conventional care, after controlling for baseline anxiety. Similarly, a study $^{31}$ on music intervention during the postoperative period after coronary bypass surgery showed a significant improvement in mood. Taken together, these studies generally demonstrate beneficial effects of music therapy on psychological outcomes in surgical patients, and no adverse outcomes or side effects have been reported.

There are certain limitations to our study, the first one being the limited sample. Secondly, the music offered to the patients was not standardized, and was in accordance with the patient's desires. The type of music can have a bearing on the results, and future studies analyzing different types of music with different rhythms and tempos can be planned to find out the best possible musical intervention in these patients. We have only studied the effect of music on postoperative pain and its efficacy in other type of pains is still a matter of research and possible future studies.
Future studies can be planned with different types of musical interventions, like live music compared with recorded music. A comparison of different types of music, like modern versus classical, can also be performed to determine the best possible intervention.

\section{Conclusion}

In the present study, we concluded that music therapy is an effective and safe complimentary modality in the management of pain and anxiety in patients undergoing nasal septal surgery. Music is effective in reducing the pain scores; music therapy is inexpensive, safe, without side effects, and it can improve the quality of life of patients undergoing nasal septal surgery.

\section{Funding}

The present study was partially funded by the Indian Council of Medical Research.

\section{Conflict of Interests}

Dr. Bakshi and Dr. Gogoularadja report grants from the Indian Council of Medical Research during the conduction of the study.

The present paper has not been sent anywhere else for publication.

\section{References}

1 Park IJ, Kim G, Ko G, Lee YJ, Hwang SH. Does preoperative administration of gabapentin/pregabalin improve postoperative nasal surgery pain? Laryngoscope 2016;126(10): 2232-2241

2 Bhattacharyya N. Ambulatory sinus and nasal surgery in the United States: demographics and perioperative outcomes. Laryngoscope 2010;120(03):635-638

3 Schnur JB, Bovbjerg DH, David D, et al. Hypnosis decreases presurgical distress in excisional breast biopsy patients. Anesth Analg 2008;106(02):440-444

4 Wang SM, Peloquin C, Kain ZN. The use of auricular acupuncture to reduce preoperative anxiety. Anesth Analg 2001;93(05): $1178-1180$

5 Simsek T, Coskun Musaoglu I, Uluat A. The effect of lidocaine and tramadol in nasal packs on pain after septoplasty. Eur Arch Otorhinolaryngol 2019;276(06):1663-1669. Doi: 10.1007/s00405019-05306-X

6 Karaman E, Gungor G, Alimoglu Y, et al. The effect of lidocaine, bupivacaine and ropivacaine in nasal packs on pain and hemorrhage after septoplasty. Eur Arch Otorhinolaryngol 2011;268(05): 685-689

7 Mutlu V, Kaya Z. Comparison of the effect of the lidocaine, tetracaine, and articaine application into nasal packs on pain and hemorrhage after septoplasty. Eur Arch Otorhinolaryngol 2018;275(10):2481-2485

8 Gooding L, Swezey S, Zwischenberger JB. Using music interventions in perioperative care. South Med J 2012;105(09):486-490

9 Sener EB, Koylu N, Ustun FE, et al. The effects of music, white noise and operating room noise on perioperative anxiety in patients under spinal anesthesia: 8AP3-3. Eur J Anaesthesiol 2010;27:133

10 van der Heijden MJ, Oliai Araghi S, van Dijk M, Jeekel J, Hunink MG. The Effects of Perioperative Music Interventions in Pediatric Surgery: A Systematic Review and Meta-Analysis of Randomized Controlled Trials. PLoS One 2015;10(08):e0133608 
11 Davis WB, Gfeller KE, Thaut MH. An Introduction to Music Therapy: Theory and Practice. Silver Spring, MD: The American Music Therapy Association; 2008

12 Palmer JB, Lane D, Mayo D, Schluchter M, Leeming R. Effects of Music Therapy on Anesthesia Requirements and Anxiety in Women Undergoing Ambulatory Breast Surgery for Cancer Diagnosis and Treatment: A Randomized Controlled Trial. J Clin Oncol 2015;33(28):3162-3168

13 Mayor S. Listening to music helps reduce pain and anxiety after surgery, review shows. BMJ 2015;351:h4398

14 Jacobson AF. Intradermal normal saline solution, self-selected music, and insertion difficulty effects on intravenous insertion pain. Heart Lung 1999;28(02):114-122

15 Megel ME, Houser CW, Gleaves LS. Children's responses to immunizations: lullabies as a distraction. Issues Compr Pediatr Nurs 1998;21(03):129-145

16 Nguyen TN, Nilsson S, Hellström AL, Bengtson A. Music therapy to reduce pain and anxiety in children with cancer undergoing lumbar puncture: a randomized clinical trial. J Pediatr Oncol Nurs 2010;27(03):146-155

17 Menegazzi JJ, Paris PM, Kersteen CH, Flynn B, Trautman DE. A randomized, controlled trial of the use of music during laceration repair. Ann Emerg Med 1991;20(04):348-350

18 Fratianne RB, Prensner JD, Huston MJ, Super DM, Yowler CJ, Standley JM. The effect of music-based imagery and musical alternate engagement on the burn debridement process. J Burn Care Rehabil 2001;22(01):47-53

19 Baghdadi ZD. Evaluation of audio analgesia for restorative care in children treated using electronic dental anesthesia. J Clin Pediatr Dent 2000;25(01):9-12

20 Schiemann U, Gross M, Reuter R, Kellner H. Improved procedure of colonoscopy under accompanying music therapy. Eur J Med Res 2002;7(03):131-134
21 Good M, Anderson GC, Stanton-Hicks M, Grass JA, Makii M. Relaxation and music reduce pain after gynecologic surgery. Pain Manag Nurs 2002;3(02):61-70

22 Keilani C, Simondet N, Maalouf R, et al. Effects of music intervention on anxiety and pain reduction in ambulatory maxillofacial and otorhinolaryngology surgery: a descriptive survey of 27 cases. Oral Maxillofac Surg 2017;21(02):227-232

23 McCaffrey R, Freeman E. Effect of music on chronic osteoarthritis pain in older people. J Adv Nurs 2003;44(05):517-524

24 Nilsson U, Rawal N, Unosson M. A comparison of intra-operative or postoperative exposure to music-a controlled trial of the effects on postoperative pain. Anaesthesia 2003;58(07):699-703

25 Urakawa K, Yokoyama K. Can relaxation programs with music enhance human immune function? J Altern Complement Med 2004;10(04):605-606

26 Smagin GN, Heinrichs SC, Dunn AJ. The role of CRH in behavioral responses to stress. Peptides 2001;22(05):713-724

27 Özer N, Karaman Özlü Z, Arslan S, Günes N. Effect of music on postoperative pain and physiologic parameters of patients after open heart surgery. Pain Manag Nurs 2013;14(01):20-28

28 Yung PM, Chui-Kam S, French P, Chan TM. A controlled trial of music and pre-operative anxiety in Chinese men undergoing transurethral resection of the prostate. J Adv Nurs 2002;39(04): 352-359

29 Lepage C, Drolet P, Girard M, Grenier Y, DeGagné R. Music decreases sedative requirements during spinal anesthesia. Anesth Analg 2001;93(04):912-916

30 Haun M, Mainous RO, Looney SW. Effect of music on anxiety of women awaiting breast biopsy. Behav Med 2001;27(03):127-132

31 Barnason S, Zimmerman L, Nieveen J. The effects of music interventions on anxiety in the patient after coronary artery bypass grafting. Heart Lung 1995;24(02):124-132 